\title{
Opioidergic control of gonadotrophin secretion in the prepubertal gilt during restricted feeding and realimentation
}

\author{
J. R. Cosgrove*, P. J. Booth and G. R. Foxcroft* \\ AFRC Research Group on Hormones and Farm Animal Reproduction, University of Nottingham \\ Faculty of Agricultural and Food Science, Sutton Bonington, Loughborough, Leics LE12 5RD, UK
}

\begin{abstract}
Summary. Prepubertal gilts, having undergone a 7-day period of feed restriction to a maintenance ration, were allocated to one of 4 treatments; restricted feeding at 09:00 and 17:00 h for an 8th day both with (Group RN) and without (Group R) administration of the opioid antagonist naloxone hydrochloride $\left(1 \mathrm{mg} \cdot \mathrm{kg}^{-1}\right.$ at $09: 30 \mathrm{~h}$ followed by $0.5 \mathrm{mg} \cdot \mathrm{kg}^{-1}$ at hourly intervals for $7 \mathrm{~h}$ ), or feed to appetite with (Group ALN) and without (Group AL) naloxone administration. Gilts were bled at 10-min intervals on Day 8 from morning to evening feed and plasma $\mathrm{LH}, \mathrm{FSH}$ and prolactin concentrations were measured by radioimmunoassay. Compared with Group $\mathbf{R}$ gilts, Group AL gilts exhibited significantly $(P \leqslant 0.05)$ higher mean and maximum LH concentrations and pulsatility, lower prolactin concentrations $(P<0.05)$ but no significant difference in FSH secretion. Naloxone significantly depressed the increase in LH after re-feeding (Group ALN) $(P<0.05)$. Once again there were no significant effects on FSH secretion. Naloxone also significantly depressed prolactin secretion in feedrestricted gilts $(P<0.05)$. These results confirm that re-feeding of feed-restricted prepubertal gilts stimulates an immediate increase in $\mathrm{LH}$ secretion and that this elevation is not mediated via a suppression of inhibitory endogenous opioidergic tone. Rather, naloxone treatment appeared to expose a latent inhibition of LH secretion. The control of $\mathrm{LH}$ secretion is distinct from that of FSH in this model.
\end{abstract}

Keywords: prepubertal gilt; realimentation; gonadotrophin; naloxone

\section{Introduction}

In a number of mammalian species a reduction of feed intake has been associated with a suppression of gonadotrophin secretion and reproductive capacity (sheep: Haresign, 1981; Foster et al., 1989; rat: Kuderling et al., 1984; Dyer et al., 1985; macaque: Dubey et al., 1986; pig: Armstrong \& Britt, 1987; Booth, 1990). Several physiological mechanisms may contribute to these phenomena and present hypotheses centre about an impairment of the hypothalamic pulse-generator (see Steiner, 1987, for review), because the pituitary of the fasted animal has been shown to exhibit an undiminished response to gonadotrophin-releasing hormone $(\mathrm{GnRH})$ challenges (Haresign, 1981; Dyer et al., 1985; Armstrong \& Britt, 1987). Booth (1990), using prepubertal gilts, has demonstrated that short-term, severe feed restriction will impair luteinizing hormone $(\mathrm{LH})$ pulsatile secretion and reproductive tract development without concomitant alterations in body weight or composition. Re-feeding of previously feed-restricted gilts rapidly elevated LH pulsatile secretion and this response could be mimicked by use of a glucose injection regimen of energetic value similar to an ad-libitum feed.

*Present address: Department of Animal Science, Faculty of Agriculture and Forestry, University of Alberta, Edmonton, Canada T6G 2P5. 
A report (Dyer et al., 1985) that the opioid antagonist naloxone reversed fasting-induced depressions in LH secretion in ovariectomized female rats has implicated an elevation of endogenous opioid tone, inhibitory to LH secretion, as a potential mechanism by which feed-restriction may compromise reproductive capacity. The existence of opioid pathways inhibitory to LH secretion in the female pig is well established. Naloxone administration elevates LH secretion in the cyclic gilt (Barb et al., 1985) and lactating sow (Barb et al., 1986; Mattioli et al., 1986) although responses appear to be dependent upon the steroid milieu of the animal and, in the prepubertal gilt, upon specific brain maturational processes (Barb et al., 1988).

The objective of this study was to elucidate whether the suppression of LH secretion observed in the feed-restricted prepubertal gilt was due to an elevation of inhibitory endogenous opioidergic tone.

\section{Materials and Methods}

Groups of littermate gilts were obtained from the University of Nottingham piggery at approximately 90 days of age and $25 \mathrm{~kg}$ liveweight. Gilts were housed in pens of approximately 20 animals on straw bedding and received a commercial grower ration and water ad libitum. At 3 weeks before transfer to experimental procedures gilts were fed to appetite twice daily at 09:00 and 17:00 h over a 1-h period. Eight sets of 4 littermates, matched for growth rate, weight and age $(78.3 \pm 7 \cdot 3 \mathrm{~kg} ; 150 \cdot 8 \pm 3 \cdot 2$ days) were selected for final allocation to treatment.

Gilts were placed in individual crates within aural and visual contact of one another and received water ad libitum. All animals underwent 7 days (Days 1-7) of restricted feeding calculated to meet their maintenance requirements (approximately $30 \%$ of individual ad-libitum feed intake) split between two feeds at 09:00 and 17:00 h. On Day 6 animals were provided with indwelling Silastic jugular cannulae under general anaesthesia.

On Day 8 littermates were allocated according to weight to one of four treatments, ensuring genetic and weight balance across treatment groups. Group R gilts remained on restricted feeding (09:00 and 17:00 h) throughout Day 8; Group RN gilts also remained on restricted feeding on Day 8 but received a $1 \mathrm{mg} \cdot \mathrm{kg}^{-1}$ injection of naloxone hydrochloride (Du Pont, Geneva, Switzerland; Sigma, St Louis, MO 63178, USA) at 09:30 h followed by $0 \cdot 5 \mathrm{mg} \cdot \mathrm{kg}^{-1}$ injections at 1-h intervals until 16:30 h. Group AL and ALN gilts were fed to appetite at 09:00 and 17:00 h on Day 8, and Group ALN gilts also received naloxone injections as described for Group RN gilts.

Blood samples $(2.5 \mathrm{ml})$ were withdrawn at 10-min intervals from 09:00 until 17:00 h into heparinized tubes and centrifuged at $1500 \mathrm{~g}$ for $20 \mathrm{~min}$. Plasma was stored at $-20^{\circ} \mathrm{C}$ until analysis for $\mathrm{LH}$, FSH and prolactin concentrations by radioimmunoassay. Following each sample cannulae were flushed with $2 \mathrm{ml}$ sterile, heparinized $\left(10 \mathrm{IU} \cdot \mathrm{ml}^{-1}\right)$ saline.

Plasma LH concentrations were quantified by an homologous double-antibody RIA. The primary antiserum was raised in a goat immunized against a purified pig LH $(\mathrm{pLH})$ preparation, SDG-2-65 $(0 \cdot 96-1 \cdot 18 \times \mathrm{NIH}$ oLH-S19, by bioassay), kindly provided by Dr S. D. Glenn. The first booster injection, 6 months after initial immunization using Freund's complete adjuvant, produced a series of antisera with good titres and specificity. The antiserum characterized in the present assay, GRF-G81-1 bound approximately $20 \%$ radiolabelled pLH in the absence of unlabelled antigen, at an initial dilution of 1:60000. Other assay methodology was as described previously (Foxcroft et al., 1987) with the following minor modifications. To enhance precipitation of antibody-bound hormone, the second antibody (donkey anti-goat gamma globulin (AGGG), raised locally) at 1:40 dilution was preincubated for $24 \mathrm{~h}$ with $10 \%(\mathrm{w} / \mathrm{v}$ ) polyethylene glycol (PEG 6000: BDH Ltd, Poole, Dorset, UK); $200 \mu$ l PEG-AGGG were added and assay tubes were then incubated for a minimum of $8 \mathrm{~h}$ at $4^{\circ} \mathrm{C}$ before centrifugation and aspiration.

Reproducible standard curves were obtained using standard potencies from 0.01 to $0.5 \mathrm{ng} \cdot$ tube $^{-1}$ of the pLH preparation and the overall limit of sensitivity, defined as $85 \%$ of total binding, was $0.13 \mathrm{ng} \cdot \mathrm{ml}^{-1}$. A standard plasma pool, routinely assayed at 50,100 and $200 \mu \mathrm{l}$, showed no significant lack of parallelism to the standard curve. The recovery of known amounts of pLH when added to pig plasma of known potency ranged from 92 to $102 \%$, confirming accuracy. The specificity of the antibody was checked by carrying out cross-reaction studies with pig prolactin and pig FSH; at $50 \%$ binding these hormones showed 0.17 and $0.88 \%$ cross-reactivity, respectively. Samples from the present experiment were assayed at $200 \mu \mathrm{l}$ in duplicate and intra- and inter-assay coefficients of variation (CV) for a series of assays $(n=9)$ including these samples were $11.5 \%$ and $15 \cdot 4 \%$ respectively.

Plasma FSH concentrations were quantified by an homologous double-antibody RIA utilizing a rabbit antiserum to pig FSH (USDA-398-04P, USDA Animal Hormone Program, Reproduction Laboratory, Beltsville Agricultural Research Centre, Beltsville, MD 20705, USA) kindly supplied by Dr D. J. Bolt; purified pig FSH was used for reference standard (USDA pFSH-B1, $0.98 \times \mathrm{NIH}$ ovine FSH-S1) and for radioiodination (USDA pFSH-PP1) by the method of Greenwood et al. (1963). The radioiodinated hormone was purified by gel exclusion chromatography (Sephadex G100).

For the assay, $300 \mu \mathrm{l}$ plasma samples or standard $(0 \cdot 39,0 \cdot 78,1 \cdot 56,3 \cdot 25,6 \cdot 25,12 \cdot 5,25,50,100,200 \mathrm{ng}$ FSH $), 50 \mu \mathrm{l}$ rabbit antiporcine FSH serum (at a dilution of $1: 7500$ in PBS containing 1:400 normal rabbit serum) and $50 \mu 1^{125} \mathrm{I}$ labelled pFSH (diluted in assay diluent to give 10000-15000 c.p.m.) were used as appropriate. All tubes were incubated at room temperature $\left(18-20^{\circ} \mathrm{C}\right)$ for $24 \mathrm{~h}$ followed by the addition of $50 \mu \mathrm{l}$ of a 1:100 dilution of anti-rabbit 
immunoglobulin antiserum (goat anti-rabbit Ig No. 539845: Calbiochem, San Diego, CA, USA) and incubated at $40^{\circ} \mathrm{C}$ for a further $24 \mathrm{~h}$. To separate bound and free ${ }^{125} \mathrm{I}$-labelled FSH, tubes were centrifuged at $2000 \mathrm{~g}$ for $30 \mathrm{~min}$, the supernatant was aspirated and the radioactivity in the pellet counted. The first antibody bound $19 \%$ of ${ }^{125}$ I-labelled FSH in the absence of unlabelled hormone. There was no significant lack of parallelism between the standard curve and three volumes $(100,200$ and $300 \mu l)$ of a pooled standard plasma sample tested in each assay.

The recovery of known amounts of USDA pFSH-B1 added to pig plasma was $97 \cdot 1 \%$. As reported by the USDA Animal Hormone Program, the cross-reactivities of the antiserum to LH (USDA pLH-B1), GH (USDA pGH-B1) and prolactin (USDA pPRL-B1) were all $<0.1 \%$. The intra-assay CV was $8.3 \%$ and the overall limit of sensitivity of the assay was $3 \cdot 3 \mathrm{ng} \mathrm{pFSH} \cdot \mathrm{ml}^{-1}$.

Plasma concentrations of prolactin were measured by the methods described by Shaw \& Foxcroft (1985). Intraand interassay CVs were $13.4 \%$ and $11 \%$ respectively. The mean sensitivity of the assay defined as $85 \%$ of total bound was $1 \cdot 8 \mathrm{ng} \cdot \mathrm{ml}^{-1}$.

\section{Statistical analysis}

LH profiles were analysed by the method of Shaw \& Foxcroft (1985) using a sliding window technique to provide minimum, mean and maximum characteristics of $\mathbf{L H}$ secretion. The use of a frequent sampling regimen allowed the adoption of the following criteria to define an LH episode, enabling an estimation of LH pulse frequency by visual appraisal of individual profiles: any increase in LH concentration within 2 sampling intervals, followed by a decline, with at least 3 sampling intervals between the defined peak and succeeding baseline, occurring at a rate approximating the half-life of the hormone. (A full discussion of the validity and relative merits of visual appraisal for the estimation of LH profiles is available in Foxcroft et al., 1988.) Analysis of treatment effects for hormone variables was undertaken by analysis of variance utilizing programs within the GENSTAT and SAS statistical packages. Due to the stratification by age and weight of the design, both these variables were fitted as covariates. Comparisons between treatment least-square means were made using Student's $t$ test.

\section{Results}

\section{Luteinizing hormone}

Feed-restricted gilts (Groups R and RN) consumed all feed offered and gilts of Groups AL and ALN fed to appetite over a 30 -min period before the first naloxone injection. Gilts receiving naloxone injections exhibited no observable behavioural responses to drug administration when compared with littermates.

Abnormally high LH and FSH secretion was observed in the gilts of Litter 215 (peak LH concentrations for each littermate being: AL 1.94; ALN 1.77; R 2.58; RN 1.68 ng.ml ${ }^{-1}$ ) and data from this litter were excluded from all analyses. This did not alter the direction of treatment differences in any hormonal characteristics measured and hence the data presented are based on an analysis of 28 gilts from 7 litters.

LH profiles of two groups of littermates from the 4 treatment groups are presented in Fig. 1, representing the extremes of variability in LH pulsatility and the consistency of treatment effects within litters. Least-square treatment group means for minimum, mean and maximum LH secretion and number of LH pulses during the 8-h bleed period are presented in Figs 2 and 3(a). There were no differences $(P>0.05)$ in minimum LH secretion between any treatment groups, suggesting no effect of realimentation or naloxone administration on basal $\mathrm{LH}$ secretion. However, mean and maximum LH secretion in Group AL gilts was higher $(P \leqslant 0.05)$ than in gilts of Group $\mathrm{R}$, confirming previous findings that realimentation rapidly elevates $\mathrm{LH}$ secretion in the feedrestricted prepubertal gilt. Additionally, Group AL gilts exhibited higher $(P<0.05)$ mean and maximum LH secretion than did gilts of Group ALN, suggesting that naloxone inhibited the elevation of LH secretion that follows realimentation. Treatment effects on LH pulsatility during the 8-h bleed period, shown in Fig. 3(a), confirmed the above observations; re-feeding elevated LH pulsatility $(P<0.05)$ while naloxone injections exerted the opposite effect $(P<0.05)$.

\section{Follicle-stimulating hormone}

There were no significant treatment effects upon FSH secretion as demonstrated in Fig. 3(b), suggesting that changes in LH secretion occurred independently of short-term changes in FSH secretion. 

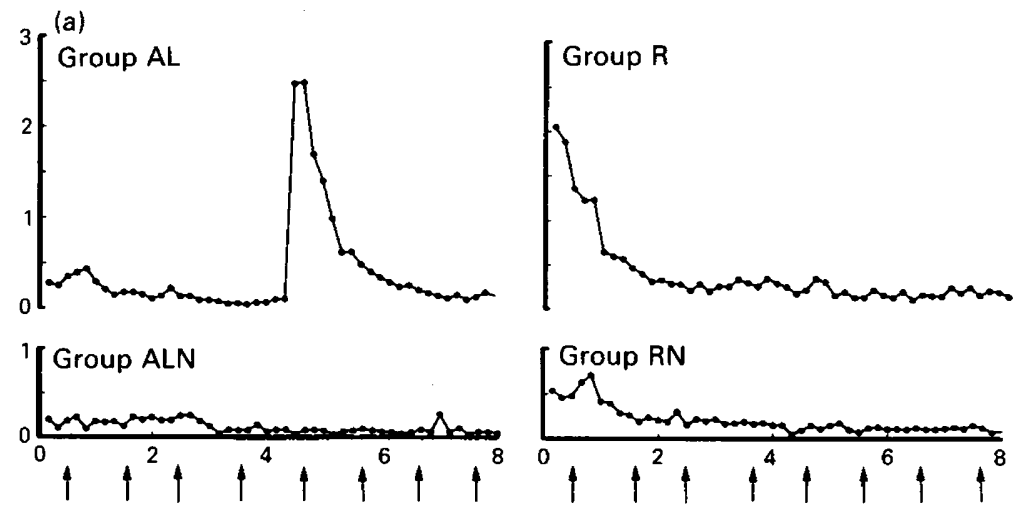

(b)
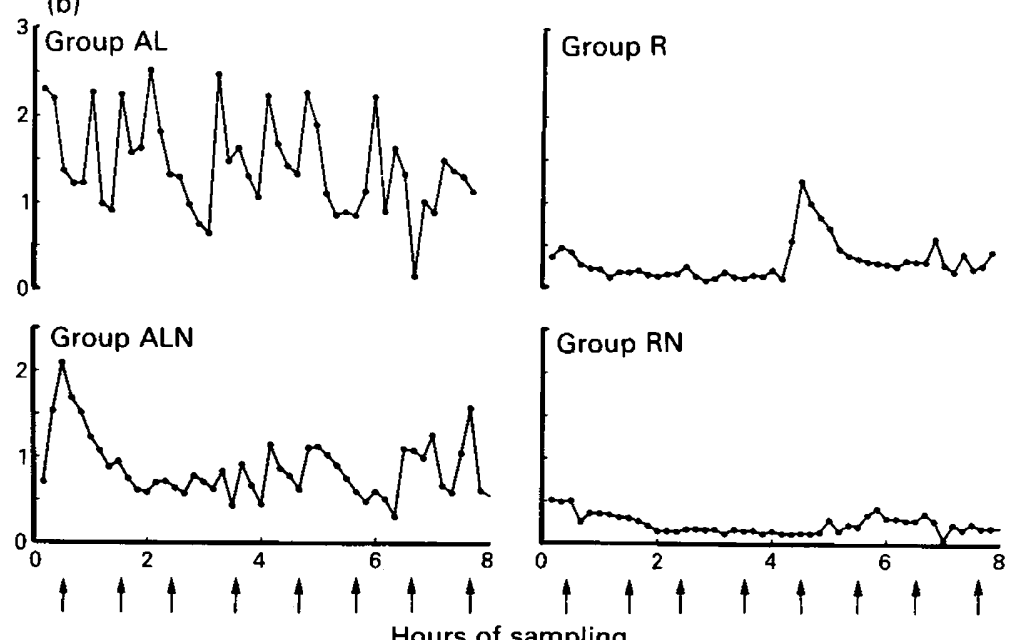

Fig. 1. Plasma LH profiles of 8 gilts of 2 litters exhibiting (a) low episodic secretion (Litter 211) and (b) high episodic secretion (Litter 217). Treatment abbreviations are as described in the text. Arrows indicate times of naloxone injection.

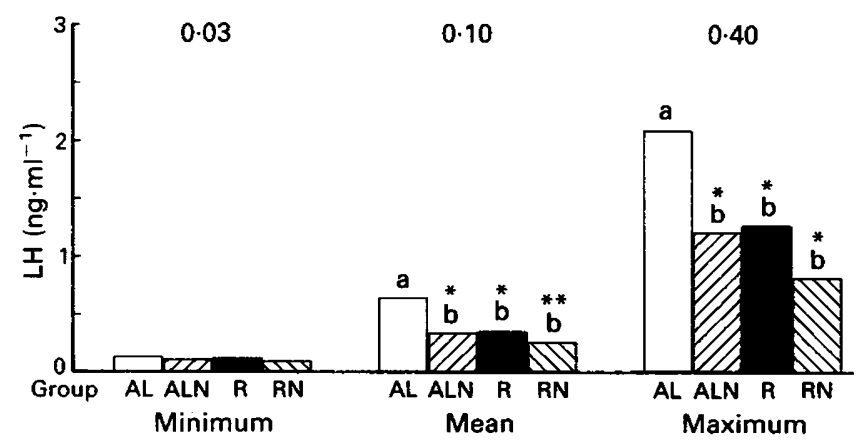

Fig. 2. Least squares means of minimum, mean and maximum LH secretion (s.e.d. above) for 4 treatments. Treatment abbreviations are as defined in the text. Bars with different superscripts are significantly different: ${ }^{*} P \leqslant 0.05,{ }^{* *} P<0.01$. 

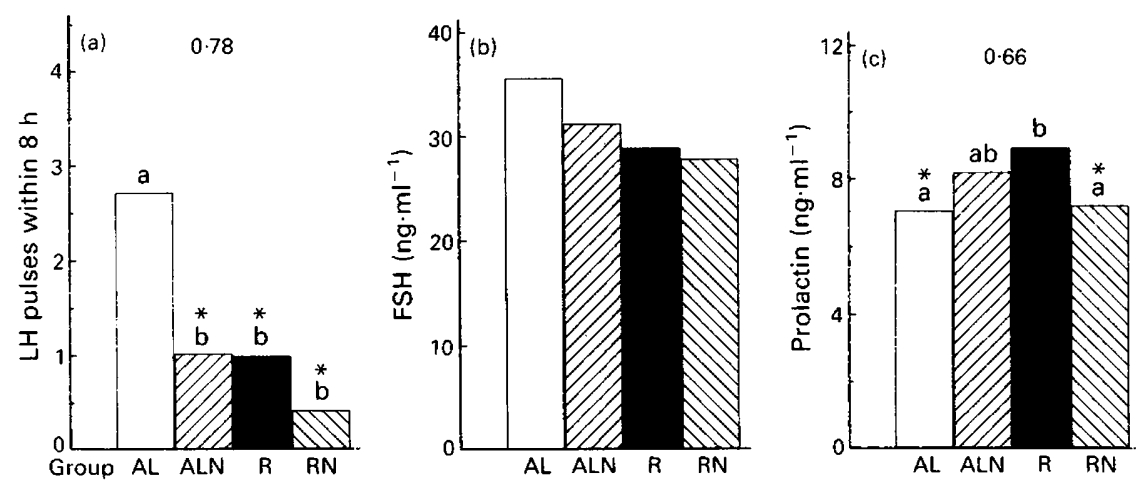

Fig. 3. Least squares means of (a) LH pulsatility, (b) FSH secretion and (c) prolactin secretion (s.e.d. above) for 4 treatments. Treatment abbreviations are as defined in the text. Bars with different superscripts are significantly different: ${ }^{*} P<0.05$.

\section{Prolactin}

Least-square treatment group means for prolactin are presented in Fig. 3(c). Prolactin secretion was elevated in feed-restricted gilts when compared with their ad libitum-fed counterparts $(P<0.05)$ and restrict-fed gilts receiving naloxone $(P<0.02)$. There was also a trend for ad libitum-fed gilts to secrete lower levels of prolactin than did ad libitum-fed animals receiving naloxone.

\section{Discussion}

The results of this study demonstrating a short-term effect of re-feeding in the 7-day feed-restricted prepubertal gilt model, evidenced by elevated LH secretion within $8 \mathrm{~h}$ of re-feeding, are confirmed by the observations of Booth (1990). The precise mechanism by which re-feeding operates to overcome LH suppression by restriction is unclear. In the female rat opioid peptides within the central nervous system have been implicated as modulators of $\mathrm{LH}$ secretion under stress conditions and during periods of restricted feeding (Corbet et al., 1982; Dyer et al., 1985; Dyer, 1988; Hollingsworth et al., 1989). Briski et al. (1984) and Dyer et al. (1985) reported an elevation in LH secretion in the male and female feed-restricted rat following administration of naloxone. Other workers, however, have failed to demonstrate effects of naloxone on LH secretion in the underfed male rat (Kuderling et al., 1984) and the nutritionally growth-limited female lamb (Ebling et al., 1990).

The results of the present study suggest that the suppression of LH secretion seen in the feedrestricted gilt cannot be explained by an elevation of inhibitory opioid tone, because naloxone failed to elevate LH secretion in Group RN gilts. However, naloxone treatment (Group ALN) inhibited the $\mathrm{LH}$ response to re-feeding observed in littermates fed to appetite (Group AL) and this response to opioid antagonism during realimentation is both a novel and unexpected observation. The possibility that the dose of naloxone administered ( $1 \mathrm{mg} \cdot \mathrm{kg}^{-1}$ followed by $0.5 \mathrm{mg} \cdot \mathrm{kg}^{-1}$ hourly) was too low to inhibit opioid tone seems unlikely, as earlier studies have adopted similar doses to elicit positive effects on LH secretion: additionally, a significant effect of naloxone was recorded albeit the reverse of that expected. Alternatively, the dose of naloxone chosen, coupled with the sub-chronic injection regimen, may have resulted in an agonistic effect of the drug as suggested by Armstrong et al. (1988) in the chronically infused lactating sow; this, however, also seems unlikely as a transient elevation in $\mathrm{LH}$ secretion would have been expected before suppression within the first hour following naloxone injection. This response is not apparent in the LH profiles presented in Fig. 1 and did not occur in any other gilts treated with naloxone (data not shown). Prolactin 
responses to administration of the antagonist to feed-restricted gilts appeared to be in line with previous studies (Barb et al., 1986; Mattioli et al., 1986), i.e. a suppression of prolactin in this group, suggesting that this dosage of naloxone was capable of eliciting a predictable physiological response. The absence of a significant decrease in prolactin in Group ALN gilts may be due to the lower prolactin status of these gilts compared with their feed-restricted counterparts, Group R gilts exhibiting significantly higher prolactin secretion.

An explanation for the observed depression of $\mathrm{LH}$ secretion by naloxone in this model is elusive. Opioids have been implicated in the control of LH secretion in the cyclic gilt (Barb et al., 1985) and in the rat (Blank et al., 1979; Bhanot \& Wilkinson, 1983; Petraglia et al., 1984; Sirinathsingi et al., 1985), sheep (Ebling \& Lincoln, 1985; Brooks et al., 1986; Currie \& Rawlings, 1987), heifer (Short et al., 1987) and women (Petraglia et al., 1986). Although the effects of various doses of the opioid antagonist naloxone in the cyclic pig have generally been to elevate $\mathrm{LH}$ secretion, this response appears to be dependent upon both the steroid milieu of the animal (Barb et al., 1986) and certain brain maturational events (Barb et al., 1988). Barb et al. (1988) failed to show any LH response to naloxone in prepubertal gilts while chronologically mature, oestrogen/progesterone-treated ovariectomized gilts showed an elevation of $\mathrm{LH}$ secretion in response to the antagonist. In contrast, a depression of $\mathrm{LH}$ secretion following similar doses of naloxone $\left(1 \mathrm{mg} \cdot \mathrm{kg}^{-1}\right)$ in the 12-week-old gilt has been observed (H. Prunier, personal communication).

The noradrenergic/catecholaminergic systems have also been implicated in the control of gonadotrophin-releasing hormone (GnRH) in the rat (Dyer \& Grossman, 1988; Hollingsworth et al., 1989) and the pig (Parvizi \& Ellendorff, 1978). It has been suggested that noradrenergic pathways both stimulatory and inhibitory to $\mathrm{GnRH}$ secretion are present in the rat and that the balance of these opposing inputs determines the level of $\mathrm{GnRH}$ and hence gonadotrophin release. The presence of circulating oestrogens may act centrally to bias this input to be stimulatory, while in the absence of this 'oestrogen switch', central noradrenaline release inhibits GnRH release (Dyer, 1988; Grossman \& Dyer, 1989; Kalra et al., 1989). Opioids have been shown to be inhibitory to central noradrenergic secretion in the rat (Grossman \& Dyer, 1989).

Our results demonstrate an elevation in pulsatile LH secretion following ad-libitum feeding in the previously maintenance-fed gilt. Assuming that this rapid rise in $\mathrm{LH}$ secretion would have no immediate effect on ovarian oestrogen secretion, systemic oestrogen levels would remain low. If an 'oestrogenic switch' were to be present in the prepubertal gilt, under the above conditions the switch would be inoperable and noradrenergic secretion would act to inhibit GnRH and hence LH secretion. Naloxone may therefore block opioid inhibition of noradrenaline and hence further inhibit LH secretion by indirect actions on GnRH neurones. This hypothesis might explain LH responses to naloxone in Group ALN gilts and the trend for decreased LH secretion in Group RN gilts. Since LH secretion in feed-restricted gilts was already suppressed, significant reductions in response to naloxone would be difficult to demonstrate. A study of the LH response of oestrogenprimed re-fed prepubertal gilts to naloxone injection would be informative.

These results suggest that the $\mathrm{LH}$ response to re-feeding of the feed-restricted prepubertal gilt may be mediated by as yet unidentified cues, e.g. by metabolic hormone changes. Booth (1990) has suggested that insulin and/or insulin-like growth factor 1 (IGF-1) may be the modulators of enhanced LH secretion in such animals and Cox et al. (1987) have shown enhanced ovulation rate in gilts treated with long- and short-acting insulin. Insulin receptors have been identified in the vicinity of GnRH-producing neurones (Havrankova et al., 1978) and Woods et al. (1979) have suggested that CSF levels of insulin represent integrated long-term reflections of humoral fluctuations and act as an effective central indicator of metabolic status. Therefore it seems likely that metabolic factors impinge upon the central regulation of LH secretion. Further study of central and ovarian responses is necessary.

In this study FSH secretion was not significantly affected by either treatment, underlining the differential secretion pattern and control of this hormone by LHRH. The study was conducted over a relatively short time period and it might be expected that short-term fluctuations in LHRH 
release would not be reflected by FSH secretion. However, a previous study of the longer-term effects of re-feeding has also failed to establish significant effects on FSH secretion (Booth, 1990).

We thank Du Pont for their kind donation of naloxone hydrochloride; Dr D. F. M. Van de Wiel, Dr J. H. F. Erkens, Dr S. D. Glenn, Dr S. Lynch, Dr D. J. Bolt and Dr K. Kochman for gifts of antigens and antisera; F. De Rensis for development of the LH assay; and G. Grant for development of the FSH assay. This work was financially supported by the Agriculture and Food Research Council. J.R.C. was supported by a Ministry of Agriculture, Fisheries and Food research studentship and gratefully acknowledges the help of the Bankers' Benevolent Fund.

\section{References}

Armstrong, J.D. \& Britt, J.H. (1987) Nutritionallyinduced anestrus in gilts; metabolic and endocrine changes associated with cessation and resumption of estrous cycles. J. Anim. Sci. 65, 508-523.

Armstrong, J.D., Kraeling, R.R. \& Britt, J.H. (1988) Effects of naloxone or transient weaning on secretion of LH and prolactin in lactating sows. J. Reprod. Fert. 83, 301-308.

Barb, C.R., Kraeling, R.R., Rampacek, G.B. \& Whisnant, C.S. (1985) Opioid inhibition stimulates luteinizing hormone and prolactin secretion in the gilt. Dom. Anim. Endocr. 2, 93-98.

Barb, C.R., Kraeling, R.R., Rampacek, G.B. \& Whisnant, C.S. (1986) Opioid inhibition of luteinizing hormone secretion in the postpartum lactating sow. Biol. Reprod. 35, 368-371.

Barb, C.R., Rampacek, G.B., Kraeling, R.R., Estienne, M.J., Taras, E., Estienne, C.E. \& Whisnant, C.S. (1988) Absence of brain opioid peptide modulation of luteinizing hormone secretion in the prepubertal gilt. Biol. Reprod. 39, 603-609.

Bhanot, R. \& Wilkinson, M. (1983) Opiatergic control of gonadotrophin secretion during puberty in the rat: a neurochemical basis for the hypothalamic 'gonadostat'? Endocrinology 113, 596-602.

Blank, M.S., Panerai, A.E. \& Friesen, H.G. (1979) Opioid peptides modulate luteinizing hormone secretion during sexual maturation. Science, $N Y \mathbf{2 0 3}$, 1129-1131.

Booth, P.J. (1990) Metabolic influences on hypothalamicpituitary-ovarian function in the pig. $J$. Reprod. Fert., Suppl. 40, 89-100.

Briski, K.P., Quigley, K. \& Meites, J. (1984) Endogenous opiate involvement in acute and chronic stress induced changes in plasma $\mathbf{L H}$ concentrations in the male rat. Life Sci. 34, 2485-2493.

Brooks, A.N., Haynes, N.B., Yang, K. \& Lamming, G.E. (1986) Ovarian steroid involvement in endogenous opioid modulation of $\mathrm{LH}$ secretion in seasonally anoestrus mature ewes. J. Reprod. Fert. 76, 709-715.

Corbet, H.J., Dyer, R.G. \& Mansfield, S. (1982) Inhibition of oestrogen-stimulated secretion of luteinizing hormone $(\mathrm{LH})$ in fasted rats is reversed by naloxone. $J$. Physiol., Lond 327, 37P, abstr.

Cox, N.M., Stuart, M.J., Althen, T.G., Bennet, W.A. \& Miller, H.W. (1987) Enhancement of ovulation rate in gilts by increasing dietary energy and administering insulin during follicular growth. J. Anim. Sci. 64, $507-516$.
Currie, W.D. \& Rawlings, N.C. (1987) Naloxone enhances $\mathrm{LH}$ but not FSH release during various phases of the estrous cycle in the ewe. Life Sci. $\mathbf{4 1}$, 1207-1214.

Dubey, A.K., Cameron, J.L., Steiner, R.A. \& Plant, T.M. (1986) Inhibition of gonadotrophin secretion in castrated male rhesus monkeys (Macaca mulatta) induced by dietary restriction: analogy with the prepubertal hiatus of gonadotrophin release. Endocrinology 118, 518-525.

Dyer, R.G. (1988) Central mechanisms regulating the periodic secretion of GnRH. Proc. 11th Int. Congr. Anim. Reprod. \& AI, Dublin, Vol. 5, 363-369.

Dyer, R.G. \& Grossman, R. (1988) Opioid modulation of the response of pre-optic neurones to stimulation of the ventral noradrenergic tract in female rats. $J$. Physiol., Lond. 400, 631-644.

Dyer, R.G., Mansfield, S., Corbet, H. \& Dean, A.D.P. (1985) Fasting impairs LH secretion in female rats by activating an inhibitory opioid pathway. J. Endocr. 105, 91-97.

Ebling, F.J.P. \& Lincoln, G.A. (1985) Endogenous opioids and the control of seasonal LH secretion in Soay rams. J. Endocr. 107, 341-353.

Ebling, F.J.P., Wood, R.I., Karsch, F.J., Vannerson, L.A., Suttie, J.M., Bucholtz, D.C., Schall, R.E. \& Foster, D.L. (1990) Metabolic interfaces between growth and reproduction: 3. Central mechanisms controlling pulsatile LH secretion in the nutritionally growth-limited female lamb. Endocrinology 126, 2719-2727.

Foster, D.L., Ebling, F.J.P., Micka, A.F., Vannerson, L.A., Bucholtz, D.C., Wood, R.I., Suttie, J.M. \& Fenner, D.E. (1989) Metabolic interfaces between growth and reproduction. 1. Nutritional modulation of gonadotrophin, prolactin and growth hormone secretion in the growth-limited female lamb. Endocrinology 125, 342-350.

Foxcroft, G.R., Shaw, H.J., Hunter, M.G., Booth, P.J. \& Lancaster, R.T. (1987) Relationship between luteinizing hormone, follicle-stimulating hormone, prolactin secretion and ovarian follicular development in weaned sows. Biol. Reprod., 36, 175-191.

Foxcroft, G.R., Haresign, W., Haynes, N.B., Lamming, G.E. \& Peters, A.R. (1988) Gonadotrophinsdomestic animals. Acta endocr., Copenh., Suppl. 288, 41-50.

Greenwood, F.C., Hunter, W.M. \& Glover, J. (1963) The preparation of ${ }^{13}$ I-labelled human growth hormone 
of high specific radioactivity. Biochem. J. 89, 114-123.

Grossman, R. \& Dyer, R.G. (1989) Opioid inhibition of brainstem projections to the medial pre-optic area in female rats. In Brain Opioid Systems in Reproduction, pp. 112-124. Eds R. G. Dyer \& R. J. Bicknell. Oxford University Press, New York.

Haresign, W. (1981) The influence of nutrition on reproduction in the ewe. 2 . The effects of undernutrition on pituitary responsiveness to luteinizing hormonereleasing hormone stimulation. Anim. Prod. 32, 257-260.

Havrankova, J., Schmechel, D., Roth, J. \& Brownstein, M. (1978) Identification of insulin in the brain. Proc. natn. Acad. Sci. USA 75, 5737-5741.

Hollingsworth, S., Mansfield, S. \& Dyer, R.G. (1989) Opioid peptides inhibit the noradrenergic input to the rostral hypothalamus to reduce $\mathbf{L H}$ secretion in fasted rats. In Neuroendocrine Perspectives, vol. 6, pp. 119-125. Eds E. E. Muller \& R. M. Macleod. Springer-Verlag, New York.

Kalra, S.P., Allen, L.G. \& Kalra, P.S. (1989) Opioids in the steroid-adrenergic circuit regulating $\mathrm{LH}$ secretion: dynamics and diversities. In Brain Opioid Systems in Reproduction, pp. 95-111. Eds R. G. Dyer \& R. J. Bicknell. Oxford University Press, New York.

Kuderling, I., Dorsch, G., Warnoff, M. \& Pirke, K. (1984) The actions of prostaglandin $E_{2}$, naloxone and testosterone on starvation-induced suppression of luteinizing hormone-releasing hormone and luteinizing hormone secretion. Neuroendocrinology 39, 530-537.

Mattioli, M., Conte, F., Seren, E. \& Geleati, G. (1986) Effect of naloxone on plasma concentrations of prolactin and LH in lactating sows. J. Reprod. Fert. 76, 167-173.
Parvizi, N. \& Ellendorf, F. (1978) Norepinephrine and luteinizing hormone secretion: intrahypothalamic and intraventricular microinjections of norepinephrine. Brain Res. 148, 521-525.

Petraglia, F., Locatelli, V., Penalva, A., Cocchi, D., Genazzini, A.R. \& Muller, E.E. (1984) Gonadal steroid modulation of naloxone-induced $\mathrm{LH}$ secretion in the rat. J. Endocr. 101, 33-39.

Petraglia, F., Porro, C., Facchinetti, F., Cicoli, C., Bertellini, E., Volpe, A., Barbieri, G.C. \& Genazzini, A.R. (1986) Opioid control of LH secretion in humans: menstrual cycle, menopause and ageing reduce effect of naloxone but not morphine. Life Sci. 38, 2103-2110.

Shaw, H.J. \& Foxcroft, G.R. (1985) Relationships between LH, FSH and prolactin and reproductive activity in the weaned sow. J. Reprod. Fert. 75, 17-28.

Short, R.E., Brooks, A.N., Peters, A.R. \& Lamming, G.E. (1987) Opioid modulation of LH secretion during the oestrous cycle of heifers. J. Reprod. Fert. 80, 213-219.

Sirinathsinghii, D.J.S., Motta, M. \& Martini, L. (1985) Induction of precocious puberty in the female rat after chronic naloxone administration during the neonatal period: the opiate "brake" on prepubertal gonadotrophin secretion. $J$. Endocr. 104, 299-307.

Steiner, R.A. (1987) Nutritional and metabolic factors in the regulation of reproductive hormone secretion in the primate. Proc. Nutr. Soc. 46, 159-175.

Woods, S.C., Lotter, E.C., McKay, L.D. \& Porte, D., Jr (1979) Chronic intracerebroventricular food intake and body weight of baboons. Nature, Lond. 282, 503-505.

Received 11 May 1990 